\title{
O POSITIVISMO PRESUMIDO DE FREDERICK SCHAUER E SUA APLICAÇÃO NA INTERPRETAÇÃO JUDICIAL DAS REGRAS DE COMPETÊNCIA CONSTITUCIONAIS
}

\author{
Emanuel Melo Ferreira
}

\section{Introdução}

O presente texto tem por objetivo demonstrar como a aplicação do positivismo presumido de Frederick Schauer contribui para o desenvolvimento do Estado Democrático de Direito a partir manutenção da separação de poderes, ao impedir a realocação de Poder especificamente no bojo do judiciário, quando este interpreta as regras de competência constitucionais. Assim, busca responder à seguinte pergunta: em que medida o positivismo presumido pode contribuir para impedir que juízes "sedentos por poder" alcancem seus objetivos?

O tema é relevante, pois refere-se ao controle de constitucionalidade judicial que tem por parâmetro regras de competência. Reconhecendo-se que há diversos dispositivos, por exemplo, na Constituição Federal de 1988 que são justamente regras que alocam poder no Legislativo, Executivo e Judiciário, a admissão de critérios interpretativos que superem tais regras pode contribuir para a concentração de poder no órgão que tem a competência de limitar essa concentração, qual seja, o Judiciário. O tema é, ainda, atual, havendo quem diga que, no Brasil, vive-se num estado de Exceção judicial (SERRANO, 2004), justamente a partir dessa indefinição entre as funções legislativa, executiva e judicial, marca do estado de exceção (AGANBEM, 2016).

O autor utilizado na pesquisa é o positivista normativo Frederick Schauer, o qual se constitui como uma das maiores referências no estudo das regras jurídicas. Sua teoria, assim, não foi escolhida por acaso: a pesquisa do professor da Universidade da Virgínia concentra-se especificamente na possibilidade de superação das regas pelos juízes, sendo o positivismo presumido uma forma de decisão judicial superior aos modelos formalista puro, particularista ou particularista sensível às regras, como adiante explicitado.

O texto inicia com a caracterização das regras efetivada pelo referencial elencado, abordando em que consistem os vícios da sub e sobreinclusão, capazes de levar à superação delas diante de situações excepcionais. Essas excepcionalidades, no bojo das regras de 
competência, por outro lado, dificilmente ocorrerão com a aplicação do positivismo presumido, tema desenvolvido no segundo tópico, o qual leva em conta os propósitos da regra para além de sua literalidade, mas impõe uma autocontenção ao julgador quando ele inicia tal empreendimento. Assim, o texto conclui apontando que o positivismo presumido é uma poderosa teoria capaz de manter a separação de poderes ao presumir a força das regras de competência.

\section{Identificação das regras jurídicas e os problemas da sub e sobreinclusão}

As regras são fruto de um processo de generalização indutiva ${ }^{1}$ : a partir da observação de determinado evento, busca-se elencar uma causa relevante para se generalizar uma determinada prescrição. $\mathrm{O}$ exemplo sempre lembrado por Frederick Schauer refere-se à norma que proíbe a entrada de cachorro em restaurante, tendo em vista que, certa vez, tal tipo de animal causara desordem no ambiente. (SCHAUER, 1991, p. 23)

Nesse sentido, Noel Struchiner (2018. p, 191), interpretando a obra de Schauer, aponta que a construção "é proibida a entrada de cachorros", como regra prescritiva ${ }^{2}$, apresenta dois elementos: um antecedente ou predicado fático e um consequente ou operador deôntico. $\mathrm{O}$ predicado fático é uma hipótese a ser verificada no mundo dos fatos e, uma vez ocorrendo, desencadeia a aplicação do consequente, com a permissão, autorização ou, no caso, a proibição de determinada conduta.

A generalização lida com a probabilidade (SCHAUER, 1991, p. 27): como certa vez um cachorro causou transtorno no restaurante, é possível que isso ocorra novamente, devendo-se proibir a entrada deles. Como um fato bruto, a regra tem a pretensão de exercer pressão sobre seu destinatário: não fosse a regra, a conduta seria outra (SCHAUER, 1991, p, 1-3). Ocorre que, a pretexto de regular uma conduta, as regras acabam deixando de regular fatos igualmente

\footnotetext{
${ }^{1}$ Para Chalmers o indutivismo consiste em postura ingênua: "De acordo com o indutivista ingênuo, a ciência começa com a observação. O observador científico deve ter órgãos sensitivos normais e inalterados e deve registrar fielmente o que puder ver, ouvir etc. em relação ao que está observando, e deve fazê-lo sem preconceitos. Afirmações a respeito do estado do mundo, ou de alguma parte dele, podem ser justificadas ou estabelecidas como verdadeiras de maneira direta pelo uso dos sentidos do observador não preconceituoso. As afirmações a que se chega (vou chamá-las de proposições de observação) formam então a base a partir da qual as leis e teorias que constituem o conhecimento científico devem ser derivadas". A ingenuidade da postura, no âmbito jurídico, será demonstrada adiante, quando estudado os fenômenos da sub e sobreinclusão. (CHALMERS, A. F. 1993. P, 2526)

${ }^{2}$ Schauer contrapõe as regras prescritivas, que determinam que algo deve acontecer, das regras descritivas, as quais apontam como certo que algo ocorrerá, tendo em vista tratarem das coisas da natureza. (SCHAUER, 1991, p. 24-27)
} 
importantes para o alcance da sua finalidade ou, por outro lado, acabam regulando condutas em excesso, as quais, de modo algum, ofenderiam a finalidade protegida. As regras, assim, são sub e sobre inclusivas (SCHAUER, 1991, p, 30-34).

Imagine-se o cachorro que é bem treinado, como um cão guia para pessoas cegas. É certo que ele é um cachorro, mas, por outro lado, não vai causar transtornos aos clientes. Nesse caso, a regra proibitiva é sobreinclusiva, pois proscreve demais. Por outro lado, imagine-se crianças barulhentas, adultos bêbados ou outros tipos de animais, como gatos que sejam também ariscos: em todas essas hipóteses, a tranquilidade dos clientes restaria ofendida, mas não se poderia dizer que, textualmente, a norma incide. Afinal, bebês barulhentos, adultos que beberam demais ou gatos não são cachorros. A regra, assim, também poderia ser subinclusiva.

O caráter sub e sobreinclusivo da regra é o ponto de partida para as considerações em torno das situações excepcionais e como o juiz deve lidar com elas, como será abordado nos pontos seguintes.

O estudo da exceção jurídica, tal qual o das regras, relaciona-se com a alocação de poder num dado sistema jurídico e, compreendendo-se o poder de excepcionar com o poder de, na prática, alterar uma regra, tem-se como importantíssimo para o direito a teorização e compreensão do fenômeno das exceções (SCHAUER, 1991B, p, 872-873).

Na teoria dos princípios, a exceção já foi analisada pela doutrina como uma maneira de se evitar uma antinomia ou conflito de regras: se uma mesma conduta é regulada por normas com conteúdo oposto, para se evitar a invalidade de uma delas, basta estabelecer uma cláusula de exceção (ALEXY, 2008, p, 92-93). O problema ganha contornos mais complexos quando não há uma exceção expressa, positivada, sendo este o tipo de exceção que importa para a presente pesquisa.

Frederick Schauer aponta como a exceção no direito é pouco aprofundada pelos estudiosos, constituindo um "tópico invisível na teoria jurídica" relacionando-a com a linguagem no sentido de que esta, muitas vezes, pode ser mais ampla que as metas pretendidas pela regra ou princípio. Assim, a exceção seria o produto da relação entre os objetivos das normas jurídicas e a linguagem através da qual elas são escritas (SCHAUER, 1991B, p, 872).

A relação entre mudanças profundas no direito e o uso progressivo das exceções pode ser um sintoma de uma patologia: o descompasso entre o direito e a realidade social. Nesse sentido, esclarece Schauer:

O uso de uma exceção é um sinal que o direito e a sociedade na qual ele destina não estão em harmonia. Se isso é uma coisa boa ou ruim depende especialmente do particular contexto substantivo, mas é sabido que aqueles que utilizam ou 
impulsionam o que agora é visto como uma exceção são aqueles que apregoam mudança no status quo, enquanto aqueles que se manifestam contra as exceções são aqueles para quem a estrutura linguística e conceitual existentes na sociedade refletem o mundo como eles desejam que ele seja (SCHAUER, 1991B, p. 893).

Em sentido mais amplo, a exceção à norma jurídica é algo que interessa para a própria noção de Estado de Direito: se a norma jurídica não é aplicada na hipótese fática nela prevista, com o recurso corriqueiro e não fundamentado em torno da excepcionalidade, a normatividade jurídica pode se converter em algo inútil, demonstrando-se uma postura de ceticismo em relação à norma jurídica tipicamente realista (HART, 2012, p, 176-183). Com o recurso frequente e injustificado à exceção, não haveria, no final das contas como separar a função judicante da legislativa e executiva, ampliando-se o problema para o nível da própria democracia, pois, como sustenta Agamben (2004, Posição 199 de 2202), a confusão entre as referidas funções numa única autoridade é uma das marcas dos estados de exceção.

As hipóteses de sub e sobreinclusão das regras apontam para fatos não albergados pela norma, pelo menos num primeiro momento, levando em conta a causa que ensejou sua criação. Elas caracterizam, assim, as exceções à regra, fenômeno que merece ser estudado para que, a partir de sua caracterização, busque-se algum critério para analisar a racionalidade da decisão judicial que pretende reconhecê-lo.

A generalização envolvida no processo de criação da regra partiu de um caso concreto, um fato. Esse fato foi valorado negativamente pela autoridade, a ponto de criar uma proibição, na esperança de que ele não se repetisse. Essa valoração aponta para a finalidade ou justificação da regra criada, cuja determinação é importante para se estabelecer com precisão quando a regra deve ou não incidir.

Ocorre que encontrar com precisão a justificação de uma regra, ou sua finalidade, nem sempre é tarefa das mais simples e, muito menos, algo evidente. No exemplo citado, a justificativa apontada para a proibição parece ser clara no sentido de evitar transtornos para os demais clientes, tendo em vista o mau comportamento que, certa vez, um cachorro causou. Schauer, no entanto, esclarece que essa seria uma justificação de primeira ordem, não se podendo olvidar de outras, dela derivada, como, por exemplo, a busca pela ampliação do lucro do dono do estabelecimento (SCHAUER, 1991, p. 73-75). Afinal, com mais clientes satisfeitos, maior seria a procura ao restaurante. Qual a justificação da regra, então: o conforto dos clientes ou a maximização dos lucros do empresário? Os princípios desempenham papel fundamental na busca pela fundamentação adequada das regras jurídicas, mas essa investigação não evita a configuração de conflitos mesmo entre a justificação subjacente à regra. 
Novamente, Schauer esclarece essa possibilidade a partir do famoso exemplo utilizado no debate entre Hart e Fuller em torno da regra "não é permito veículos no parque" (SCHAUER, 1988, p.533-534). Quais as justificativas para tal regra? Seria possível pensar na busca por tranquilidade e paz entre os usuários do parque, afetada pelo barulho dos veículos, mas também seria possível cogitar acerca da necessidade de preservação do meio ambiente, evitando-se a poluição. Nesse sentido e adaptando o exemplo, imagine-se a situação de um carro movido a eletricidade: ele ainda faz barulho quando ligado, atraindo a proscrição determinada pela primeira justificação apontada, mas, por outro lado, não polui o meio ambiente, eis que não emite gás carbônico, indo ao encontro, portanto, da segunda justificação.

Dependendo de qual seja a justificação mais adequada para o caso, o resultado será necessariamente diferente. $\mathrm{O}$ ponto a ser ressaltado com essa digressão é que o recurso à justificativa por trás da regra, por si só, não garante a superação de eventuais absurdos ou conflitos, pois o conflito pode continuar existindo entre os propósitos da regra. Logo, a regra em si merece ser levada mais a sério e não simplesmente desconsiderada, como modelos particularistas de decisão, adiante estudados, o fazem.

Humberto Ávila (2014, p, 141) apresenta modelo para se estabelecer quando uma regra pode ser superada. Ele aponta que tal modelo é bidimensional, pois leva em conta aspectos materiais, com o preenchimento de certas condições de conteúdo, e procedimentais, com a observância de requisitos de forma. Assim, para uma que se justificasse a superação de uma regra num determinado caso concreto, a operação envolvida: a) não poderia ir de encontro à finalidade subjacente à regra, sendo este o aspecto material; b) não poderia gerar insegurança jurídica a partir da possível multiplicação de julgados afastando a regra em situações semelhantes. O caso, assim, deveria ser único, realmente excepcional, de modo que, somente diante das condições especificamente nele dispostas, poderia ocorrer a superação da regra ${ }^{3}$.

Em se tratando de regras de conduta, pode-se admitir que tal método aponte para possibilidade de superação, diante das circunstâncias do caso concreto, como abordado por ele. Quando se está diante de regras de competência constitucionalmente previstas, por outro lado, é difícil imaginar alguma situação em que, com a superação de tal regra, não tenha,

\footnotetext{
${ }^{3} \mathrm{O}$ exemplo por ele citado diz respeito à certa regra tributária que prevê a inclusão de contribuinte em programa de benefício fiscal se este não for importador. Em determinada situação, uma pequena fábrica importa quatro pés de sofás, uma única vez. Tem-se o predicado fático da regra, mas é correto que este não incida e ela seja superada: tal fato isolado não vai de encontro ao propósito subjacente à regra, qual seja, promover a produção nacional das pequenas empresas, pois, ao invés disso, garante tal finalidade e, além disso, não haverá risco à segurança jurídica, sendo difícil supor uma relevante multiplicação de demandas diante de situação tão específica. (ÁVILA, 2014,
} 141) 
necessariamente: a) a ofensa aos propósitos ínsitos à separação de poderes, relacionados à alocação de poder capaz de prevenir o surgimento de instâncias soberanas, mesmo no Poder Judiciário; b) a promoção de insegurança jurídica, não se podendo prever quando o judiciário usurpará a competência do constituinte.

\section{O positivismo presumido e as regras de competência}

Este texto, reitere-se, vai criticar justamente a postura pós-positivista que admite a possibilidade de juízes alterarem as regras constitucionais ao seu bel prazer, mesmo quando se está diante de direitos fundamentais individuais, a partir de expedientes como a transformação de regras constitucionais em princípios jurídicos unicamente para, através de ponderação, alterar uma norma jurídica legitimamente posta pelo constituinte originário.

É seguindo essa linha de raciocínio que se pode lançar uma crítica às variadas práticas do denominado neoconstitucionalismo. Segundo síntese precisa de Humberto Ávila, as marcas centrais de tal corrente de pensamento, a qual anda de mãos dadas com o pós-positivismo ${ }^{4}$, são estabelecidas a parir da superação ou do barateamento: a) das regras pelos princípios; b) da subsunção pela ponderação; c) da justiça geral pela particular; d) do Poder Executivo e Legislativo pelo Poder Judiciário (ÁVILA, 2009, p, 1). Essas características apontam manifesta confusão entre as funções estatais executiva, legislativa e judiciárias, configurando, como dito, manifestação do Estado de Exceção. (AGAMBEN, 2004, posição 199)

Uma das decorrências dessas leituras "pós-positivistas" do texto constitucional é perceptível a partir do desprezo que o STF por vezes demonstra às interpretações mais próximas do sentido literal. $\mathrm{O}$ argumento muitas vezes utilizado pela Corte para se afastar da literalidade diz respeito às pretensas consequências absurdas que tal interpretação pode acarretar. Tem-se a tensão, assim, entre a literalidade e os propósitos da norma constitucional. Demonstrar-se-á que tal argumento é equivocado, apontando que, muitas vezes, a evocação aos pretensos resultados absurdos não passa de estratégia para legitimar uma alteração na Constituição não admitida pelo constituinte originário. Argumentações judicias desse tipo propõem interpretações que privilegiam os princípios em detrimento das regras constitucionais, transformando casos constitucionais fáceis em casos difíceis unicamente para legitimar o uso retórico dos princípios.

\footnotetext{
${ }^{4} \mathrm{O}$ pós-positivismo a ser criticado neste texto é aquele de perfil idealista, na caracterização de Bruno Torrano, a saber, um pós-positivismo que confere ao juiz o papel de "fazer justiça" no caso concreto, conferindo poderes não jurídicos a tais autoridades. (TORRANO, 2015, p, 15)
} 
O texto desenvolve, assim, teses prescritivas acerca da atuação judicial. Ou seja, aponta como juízes devem interpretar o Direito no contexto específico das regras constitucionais em análise quando do controle de constitucionalidade. É neste momento que se faz necessário aprofundar o estudo da vertente normativa do positivismo jurídico.

Tom Campbell assim define o positivismo jurídico normativo, também denominado, na sua construção, como positivismo ético:

\begin{abstract}
Positivismo Ético é o rótulo escolhido para identificar o tipo de teoria que se concentra nas funções éticas e nos pré-requisitos de modelos positivistas do Direito. A teoria jurídica do Positivismo Ético (daqui em diante PJE) não é uma visão analítica sobre a semântica do "Direito" ou o sentido profundo do discurso jurídico, nem é uma teoria descritiva/explicativa sobre o melhor caminho para entender o Direito e suas funções sociais. Ao invés disso, PJE é uma teoria moral sobre o exercício do poder político o qual é visto como uma atividade que busca o controle e a coordenação, num modo moralmente defensável, da conduta de um grande número de pessoas. O foco central do PJE no interior da filosofia política é o próprio modus operandi do Estado como instituição principal através da qual o poder político é exercido no mundo moderno. O quadro para sua análise é a discussão sobre a forma aceitável do uso organizado do poder coletivo sobre toda a sociedade. PJE é, portanto, essencialmente uma teoria crítica (justificatória/condenatória) do estado e do processo político contemporâneo.
\end{abstract}

Num breve e altamente simplificado sumário, PJE apresenta um modelo desejável de Direito de acordo com o qual é uma condição presumida de legitimidade do governo que ele funcione através da mediação de específicas regras capazes de serem identificadas e aplicadas pelos cidadãos e agentes públicos sem o recurso a controversos pressupostos políticos pessoais ou grupais, crenças ou compromissos. ${ }^{5}$ (CAMPELL, 2016, posição 131 de 7081)

Já é possível perceber, na breve apresentação lançada neste ponto, que o positivismo ético ou normativo não é uma tese descritiva do Direito, como muitas das correntes do positivismo clássico se apresentavam, de John Austin, passando por Hans Kelsen até Hebert Hart. Suas teses centrais são lançadas por autores como o mencionado Tom Campbell, Jeremy Waldron e Frederick Schauer. Partindo do trecho transcrito, é possível perceber, introdutoriamente, algumas de suas teses centrais: a) defesa do caráter normativo e não

\footnotetext{
${ }^{5}$ No original: "Ethical Positivism' is the label chosen to identify the sort of theory that centres on the ethical functions and prerequisities of positivist models of law. The legal theory of Ethical Positivism (hereafter LEP) is not an analytical view about the semantics of 'law' or the deep meaning of legal discourse, nor is it a descriptive/ explanatory theory about the best way to understand law and its social functions. Rather, LEP is a moral theory about the exercise of political power which it views as the activity of seeking to control and coordinate in a morally defensible manner the conduct of large numbers of people. The particular focus of LEP within political philosophy is the proper modus operandi of the state as the main institution through which political power is exercised in the modern world. The framework for its analysis is a discussion of the acceptable form of the organised use of collective power over a whole society. LEP is thus essentially a critical (justificatory/ condemnatory) theory of the state and contemporary political process.

In brief and highly simplified summary, LEP presents an aspirational model of law according to which it is a presumptive condition of the legitimacy of governments that they function through the medium of specific rules capable of being identified and applied by citizens and officials without recourse to contentious personal or group political presuppositions, beliefs and commitments". (CAMPBELL, 2016, posição 131 de 7081)
} 
descritivo da teoria do Direito; b) necessidade de legitimação dos governos a partir da uso do poder político mediado pelas regras jurídicas, as quais apresentam um papel mais decisivo na teoria que os princípios, sem desconsiderá-los; c) postura ética tanto dos agentes públicos como dos cidadãos os quais devem recorrer ao Direito, através de tal mediação baseada em regras, para a regência de suas condutas no espaço público, não admitindo, assim, a intromissão da moral individual em assuntos coletivos.

Desde já, deve-se fazer um esclarecimento semântico sobre o uso da expressão "normativo", no âmbito da teoria do Direito proposta. Seu sentido não deve ser confundido com o do positivismo que identifica o Direito com normas, ao invés de fatos brutos como poder, comando e sanções. Nesse sentido, seria "normativo" o positivismo de Hart e Kelsen (WALDRON, 2005, posição 8013), quando, para o que interessa nesta pesquisa, é a consideração dessas correntes como expressões do positivismo descritivo. Para evitar essa possível confusão, Tom Campbell prefere a expressão "positivismo ético" ao invés de "normativo", sustentando que a expressão "ético" deve compreender um sistema de razões morais de segunda ordem, prevendo papeis institucionais a serem efetivados por parte de todos os participantes da vida social, como juízes, advogados, policiais e os próprios cidadãos. Nesse sentido ético, a moral no campo institucional seria distinta da moral pessoal, devendo tais atores subjugar sua moral individual acerca do que seria o "bom Direito" em favor de um compromisso moral em obedecer ao Direito formalmente "bom". (CAMPBELL, 2016, p,175)

Waldron (2005, posição 8029), por sua vez, prefere a expressão "normativo", entendendo que o termo "ético" pode conotar padrões de valoração da conduta pessoal, ao invés de compor padrões normativos para avaliar instituições. A preferência nesta pesquisa também recairá sobre o termo positivismo normativo, entendido o aspecto normativo como uma prescrição que propõe como o sistema jurídico deveria ser. (WALDRON, 2005, posição 8029) E o que prescreve o positivismo normativo? Waldron (2005, posição 8063) esclarece: o positivismo normativo vai estipular que juízes devem decidir casos sem referência à moral. Ou seja, o positivismo normativo prescreve o positivismo excludente.

A leitura proposta nesta pesquisa acerca de diversos dispositivos da Constituição, tais como a separação de poderes, soberania popular ou mesmo o regime democrático, no sentido de limitar a atuação judicial, demanda um redimensionamento do Poder Judiciário totalmente compatível com as ideias do positivismo jurídico normativo. Nesse sentido, sustentar-se-á a necessidade de juízes interpretarem e aplicarem as leis como cuidadosas formulações que apresentam escolhas políticas controversas, definidas e decididas no bojo do processo 
legislativo. Logo, as cortes não podem se converter em "simples arenas para a determinação de um resultado que os participantes considerem social ou economicamente desejáveis"6. (CAMPBELL, 2016, Posição 252)

Para alcançar esse fim, o papel das regras é essencial, pois elas têm maior possibilidade de apresentar clareza, especificidade e consistência ${ }^{7}$, quando comparada com os princípios. Evidentemente, estes se fazem presentes na interpretação de diversos textos normativos, especialmente presentes na Constituição, mas a tese a ser combatida com a contraposição entre regras e princípios é a de que estes, muitas vezes, são utilizados, independentemente do conteúdo das regras vigentes, com a finalidade de "fazer justiça" de acordo com a moral do julgador. Dimitri Dimoulis aponta este inaceitável uso dos princípios, sendo a "finalidade política do pós-positivismo que indica seu caráter problemático”. (DIMOULIS, 2006, p. 62)

As regras, como visto, são normas jurídicas eminentemente descritivas, as quais, como dito, regulamentam condutas ou atribuem poder. Há vários modelos que buscam explicar a fundamentação das decisões judiciais que se deparam com a aplicação de regras, tais como: a) o formalista ou baseado em regra; b) o particularista; c) o particularista sensível às regras; d) o positivismo presumido (SCHAUER, 1991C, p, 647-651; 674-679). Como ressaltado anteriormente, sustentar-se-á que o modelo proposto pelo positivismo presumido é aquele que mais promove a proteção à Constituição quando se está diante da aplicação de regras de competência. Para sustentar tal tese, deve-se, inicialmente, esclarecer em que consistem os modelos antes citados.

Os modelos formalista e particularista estão nos extremos dessa distinção. O primeiro sustenta a correção de uma decisão judicial quando esta aplica a regra pura e simplesmente, sem fazer qualquer consideração acerca da justificativa ou propósito por ela almejados. É um modelo, assim, que pode gerar resultados absurdos ou injustos, mas que tem a virtude da previsibilidade e segurança (SCHAUER, 1991C, p, 650).

O modelo particularista, por sua vez, está no extremo oposto do modelo formalista. Ele apresenta esse nome porque sustenta como correta a decisão judicial fundamentada unicamente nas particularidades do caso concreto, buscando o melhor resultado numa perspectiva moral, política, econômica ou social, buscando os propósitos subjacentes à regra sem qualquer

\footnotetext{
${ }^{6}$ No original: "Law courts should not be simply arenas for the determination of an outcome that the participants deem socially or economically desirable". (CAMPBELL, 2016, Posição 252)

${ }^{7}$ Características apontadas por Tom Campbell não para opor as regras aos princípios, já que considera aquelas como "a melhor expressão de uma decisão baseada em princípios" ("the best expression of principled decision making”). (CAMPBELL, 2016, Posição 236)
} 
preocupação com a literalidade desta. É um modelo que não admite os resultados absurdos ou injustos, apostando na virtude dos juízes para alcançar tais finalidades (SCHAUER, 1991C, p, 648).

O modelo particularista sensível às regras e o positivista presumido, por outro lado, situam-se entre esses extremos. O particularista sensível às regas busca a melhor solução para o caso, mas, no balanço de razões, inclui o valor da regra como instrumento para segurança jurídica. Logo, diferentemente do modelo particularista puro, o valor da regra é levado em conta (SCHAUER, 1991C, p, 650).

Finalmente, tem-se a tese central de Frederick Schauer, consistente no positivismo ou formalismo presumido. Tal teoria apregoa que as regras constituem uma presunção não absoluta para o julgador: elas devem ser aplicadas, mas, diante de uma situação absurda ou injusta, o melhor resultado deveria ser buscado. O foco, assim, é na aplicação da regra, mesmo que ela determine resultados que não sejam os melhores. Somente em casos excepcionais, elas poderiam ser afastadas (SCHAUER, 1991C, P, 674-679).

O modelo formalista puro, no que tange à interpretação das regras de competência, é o modelo que mais promove segurança e limita a concentração de poder pois faz com que julgadores fundamentem concisa e precisamente os casos fazendo referência, unicamente, à literalidade da regra. Ao evitar argumentações baseadas em princípios que buscam as justificativas ou propósitos das regras, tem-se com clareza a aplicação da regra, não se cogitando de razões que possa contribuir para sua superação.

No entanto, na prática do STF, não é essa a forma de argumentação que se encontra mesmo nos casos em que as regras de competência são respeitadas. Mesmo quando se tem a aplicação da regra no seu sentido literal, os julgadores recorrem a algum argumento de princípio para justificá-la. Por exemplo, quando o STF entendia que o AGU deveria defender a constitucionalidade do ato impugnado no controle de constitucionalidade sem qualquer exceção, era comum a invocação de elementos para além da literalidade da regra, tais como: a) necessidade de promover o contraditório; b) levar a sério a presunção de constitucionalidade da lei ou ato normativo (ADI 72, Relator Ministro Sepúlveda Pertence ) ${ }^{8}$. Logo, o modelo

\footnotetext{
${ }^{8}$ Ementa: "Erigido curador da presunção de constitucionalidade da lei, ao Advogado-Geral da União, ou quem lhe faças às vezes, não cabe admitir a invalidez da norma impugnada, incumbindo-lhe, sim, para satisfazer requisito de validade do processo da ação direta, promover-lhe a defesa, veiculando os argumentos disponíveis". DJ 25/05/90. O Ministro Relator, seguido pelo Tribunal, apontara a condição de curador da constitucionalidade da lei atribuída constitucionalmente ao AGU, não cabendo emitir parecer para procedência da ADI.
} 
formalista, mesmo com inegáveis méritos, não é o que explica mais precisamente a prática judicial brasileira.

Os modelos particularista e sensível às regras, como já dito, apresentam virtudes e defeitos. Através deles, injustiças podem ser evitadas ou potencializadas, dependendo unicamente do julgador, eis que as regras não apresentam aptidão de bloquear a moral judicial, constrangendo e pressionando o juiz a segui-la mesmo quando não concordasse com seu conteúdo. São modelos que, na intepretação das regras de competência, poderiam gerar concentração de poder: se o Poder Judiciário, diante do caso concreto, entende pela caracterização da exceção, atribuindo-lhe uma competência não prevista constitucionalmente, o órgão que deveria limitar o poder acaba por ampliá-lo, atuando em benefício próprio.

É nesse sentido que não se pode considerar a eficácia de trincheira das regras como algo essencialmente ruim:

Em suma, está claro que as regras criam obstáculos, mas isso não precisa ser considerado sempre como algo ruim. Pode ser um prejuízo quando aqueles encarregados de decidir são sábios que sensivelmente consideram todos os fatores relevantes enquanto precisamente perseguem o bem. Entretanto, elas podem ser um ativo para restringir órgãos decisores desorientados, incompetentes, maus, sedentos por poder ou simplesmente enganados, os quais o próprio senso do que seja bom pode divergir daquele preconizado pelo sistema que eles servem. O problema, claro, é a dificuldade em determinar quais dessas caracterizações adequam-se aos decisores; devemos então decidir a extensão na qual queremos desabilitar os bons decisores em ordem de, simultaneamente, desabilitar os maus. (SCHAUER, 1988. P. 543.)

O modelo particularista na interpretação das regas de competência tem sido utilizado pelo STF em diversos casos: a) na atribuição do status supralegal aos tratados de direitos humanos, criando exceções às regras que aproximam tais normas da legislação ordinária com base em princípios ou direito estrangeiro; b) na admissão do controle judicial preventivo sobre projetos de lei, mesmo diante da regra que limita tal controle às emendas constitucionais, não se atentando adequadamente acerca da possibilidade de superação política da inconstitucionalidade formal; c) no reconhecimento da eficácia expansiva de certas decisões proferidas no bojo do controle difuso, mesmo diante da já citada regra do art. 52, X da Constituição. Em todos esses casos, praticamente nenhuma consideração acerca do valor da segurança jurídica que tais regras promovem foi elaborada pela Corte. Eis a razão para caracterização de tais decisões como particularistas, aproximando-se mais desta que o modelo particularista sensível às regras.

Resta, finalmente, a análise do formalismo presumido preconizado por Schauer, o qual pode não ser a melhor forma de decidir acerca de todas as questões num determinado sistema jurídico. Ele mesmo reconhece isso, sem explicitar quais normas seriam o objeto central dessa 
forma de decisão. Este texto, como já dito, sustenta que a aplicação central de tal formalismo ou positivismo presumido diz respeito às regras de competência, para além das regras de conduta em geral.

Schauer, inicialmente, procura reabilitar o formalismo como teoria jurídica respeitável, desenvolvendo ao final a primeira versão do que denomina "formalismo presumido". Nessa linha, ele busca refutar a ideia de que formalismo, por si só, seria algo necessariamente ruim, imagem amplamente difundida na teoria jurídica contemporânea ${ }^{9}$ (SCHAUER, 1988). O formalismo que, como visto, caracterize-se pela aplicação de regras, pode ser algo valoroso para o direito, como já antecipado anteriormente, pois teria o mérito de limitar atuação de juízes orientados pela busca desenfreada pelo poder.

Os prolegômenos do positivismo presumido vão surgir a partir dessa investigação do autor em torno de formas aceitáveis de formalismo, partindo da premissa de que as regras apresentariam não uma restrição absoluta aos julgadores, mas sim graus de restrição que, dependendo do caso e dos resultados extremamente absurdos gerados pela aplicação literal, ela poderia ser afastada. A restrição envolvida na aplicação da regra seria, assim, presumida (SCHAUER, 1988, p, 544-547).

Três anos após a publicação dessa primeira versão inicial do positivismo presumido no texto Formalism, Schauer esclarece e aprofunda sua teoria no contexto daquelas outras formas de decisão já citadas. Em Rules and the rule of law, o autor explicita sua teoria a partir da constatação de que os críticos do positivismo, como Dworkin, apontam a existência de diversas decisões judicial que não aplicam a regra em si, mas as justificativas ou princípios que as fundamentariam, como ocorrido no caso Riggs x Palmer já citado.

Schauer (1991, p, 675) sustenta que pode explicar porque decisões desse tipo, que aplicam um princípio como aquele no qual "ninguém pode se beneficiar da própria torpeza" ao invés de uma regra, podem conviver com outros tipos de decisão que fazem a argumentação oposta, concluindo pela aplicação da regra e não do princípio. Situações potencialmente conflitantes desse tipo ocorreriam devido à já citada força presumida das regras, elaborando o autor, neste momento, o conceito de presunção justificatória.

\footnotetext{
${ }^{9} \mathrm{O}$ autor não busca fazer uma defesa geral do formalismo, à medida em que critica decisões que, por exemplo, mascaram a existência real de escolha para o julgador sob o falso argumento de aplicação de um silogismo. É essa a crítica contra decisões como Lochner v. New York (1905), a qual, para julgar inconstitucional as normas sociais aprovadas que buscavam proteger a relação trabalhista, a Suprema Corte Americana limitou-se a pontar que: a) a liberdade de contratar é prevista constitucionalmente sem limitações; b) empregador e empregado contrataram entre si; c) logo, não há qualquer limite que a lei possa estabelecer. Esse é um silogismo formalista criticável porque desconsidera a ampla liberdade de escolha e avaliação que o julgador tem ao interpretar a palavra "liberdade", com profundas implicações políticas, econômicas e sociais envolvidas. (SCHAUER, 1988)
} 
A presunção justificatória está relacionada ao peso que as razões possuem num eventual balanço, existindo aquelas mais persuasivas ou mais importantes que outras. As regras, nessa linha de raciocínio, apresentariam uma presunção justificatória em torno da utilização de uma razão que fosse mais forte que outra. Como se trata de uma presunção em torno da aplicação da literalidade da regra, ela poderia ser superada, mas somente diante de uma razão que evitasse o resultado extremamente errado. Em outras palavras: há presunção em torno da razão que leve à aplicação da regra em si e não ao seu propósito, mesmo quando a regra conflita com os propósitos de normas sociais mais amplas, o fazendo, no entanto, não de modo extremo. Seria um erro simples, não extremo ou grosseiro, aplicar a regra em si (SCHAUER, 1991C, p, 675).

O positivismo presumido tem o mérito de não admitir o engajamento ativo do julgador na procura por tais razões que possa levar à superação da regra. Ele admite que isso possa ser feito, mas, agindo como uma espécie de "simplificador psicológico" (SCHAUER, 1991C, p, 677) na mente do julgador, aconselha-o a promover "olhares casuais", "checagens preliminares", "vislumbre" ou uma mera "espiada" na busca por possíveis razões que justifiquem a não aplicação literal da regra (SCHAUER, 1991C, p, 677).

É essa postura de contenção e não ativismo controlado que diferencia o positivismo presumido do modelo particularista sensível às regras. Schauer, mantendo a diferenciação após crítica de Postema, sustenta que, apesar de as regras serem levadas em conta no balanço efetivado pelo modelo particularista, a presunção em torno delas possui um peso menor ou quase inexistente em tal modelo, pois ele admite que o próprio valor da regra como norma capaz de gerar segurança jurídica a partir da previsibilidade, clareza e eficiência seja sempre ponderado, em cada caso.

No modelo particularista, a regras nem sempre, assim, teriam força para evitar o aumento de poder por parte dos decisores, já que a ponderação envolvida poderia colocar em xeque essa própria característica da regra. No modelo preconizado pelo positivismo presumido, por outro lado, as regras sempre teriam alguma força, muito embora não fossem conclusivas (SCHAUER, 1991C, p 677-678, nota de rodapé nº 71)

Um exemplo pode ajudar na diferenciação entre as formas de argumentação baseadas em regra. Imagine-se o caso relacionado ao papel do Senado Federal no controle de constitucionalidade. $\mathrm{O}$ art. 52, $\mathrm{X}$ da Constituição apresenta regra dispondo que é competência do Senado federal suspender a execução, no todo ou em parte, de lei declarada inconstitucional por decisão definitiva do Supremo Tribunal Federal. 
Em determinado caso no qual essa regra fosse colocada em questão, com alguma parte argumentando que o papel do Senado deveria ser compreendido, por exemplo, como o de mero publicador da decisão do STF, seria possível imaginar os seguintes padrões argumentativos:

a) formalista puro - "de acordo com o art. 52, X da Constituição, a competência do Senado é clara, podendo tal órgão suspender a lei, não se cogitando de qualquer atividade como a de publicação. A literalidade do dispositivo é suficiente para afastar qualquer resultado em sentido contrário".

b) Particularista - "a isonomia no tratamento de casos semelhantes, mas ainda não decididos pelo STF eis que se encontram perante as demais instâncias do Poder Judiciário é razão suficiente para a eficácia expansiva imediata da decisão da Corte. Logo, nenhuma consideração em torno do art. 52, X pode autorizar resultado diverso do que ora preconizado."

c) Particularista sensível às regras - "está em jogo valores como isonomia e o valor formal da segurança jurídica com a alocação de poderes no legislativo, mas o peso deve recair nas particularidades do caso, não sendo justo que a parte aguarde seu caso chegar ao STF para, só neste somente, ver seu direito alcançado. Teorizações abstratas sobre a segurança jurídica não podem impedir tal resultado.

d) Positivismo presumido - "realmente, está em jogo possível resultado absurdo com a falta de isonomia no sistema. No entanto, esse resultado não é extremamente errado, pois: a) o Senado Federal pode suspender a norma, não sendo correto pressupor que ele não vai atuar assim; b) não se trata de teorização abstrata em torno da segurança jurídica, mas sim de preservar a alocação de poderes e impedir que o STF concentre competências vedadas pelo próprio Constituinte".

Perceba-se a diferença argumentativa: a) no primeiro caso, o julgador limitou-se a indicar a regra referente ao art. 52, X, sem qualquer referência aos objetivos ou propósitos por trás de tal competência; b) no extremo oposto, o julgador particularista sequer cita a literalidade da regra, afiançando-se unicamente na injustiça do caso com a quebra de isonomia; c) o primeiro modelo intermediário, particularista sensível às regras, mostra uma preocupação com o valor formal da regra, mas rapidamente superado ao apontar que se trata de uma mera abstração; d) finalmente, o modelo positivista presumido reconhece, num daqueles 
"vislumbres" preliminares, que pode haver ofensa à isonomia, mas que esse resultado não é, necessariamente, extremamente equivocado, pelas razões que invoca.

Os modelos de argumentação estudados não existem de modo estanque num dado sistema jurídico. Schauer reconhece que o modelo formalista presumido pode ser melhor utilizado em certas partes do sistema do que em outras, sem especificar quais seriam essas partes (SCHAUER, 1988, p, 547). Este trabalho sustenta que tal modelo é o que melhor explica e normatiza a interpretação judicial das regras de competência constitucionais: a) explica melhor porque, na prática, a argumentação judicial não se contenta com a mera menção à literalidade da regra de competência; b) normatiza convincentemente a atuação judicial ao levar a sério a necessidade de alocação de poder para se evitar a formação de soberanos, abrindo espaço para argumentação em busca dos propósitos da norma unicamente para determinar a aplicação da própria regra diante de erro não grosseiro, sem o intuito ativista já pré-concebido mentalmente pelo julgador.

Ainda pode ter ficado em aberto a questão: e quando se estará diante de um erro daquela magnitude, extremamente grave capaz de levar à superação da regra? No bojo das regras de competência constitucionais, objeto central desta pesquisa, dificilmente haverá um resultado absurdo quando a aplicação literal da regra previna a concentração de poder, especialmente no poder judiciário. Assim, é até possível cogitar da superação de regras de competência infraconstitucionais, ante violação de regras constitucionais. No entanto, a necessidade de alocação de poder e desconcentração deste, especialmente, no Poder Judiciário, justifica a afirmação de que não se estaria diante de erro extremo na aplicação literal de regra de competência constitucional.

\section{Conclusões}

O positivismo presumido, ao conferir uma força presumida às regras jurídicas, apresenta a vantagem de afastar resultados absurdos na aplicação delas, evitando que, sempre, o sentido literal prevaleça, mesmo quando os propósitos da regra apontem para sentido diverso. Além de tal vantagem, a presunção estabelece forte autocontenção judicial, buscando operar até mesmo no campo psicológico: o juiz que a utilize não deve se engajar em postura ativista na busca pelos propósitos da regra.

O papel do juiz, presumindo a força da regra, é meramente vislumbrar, num primeiro momento, os possíveis resultados absurdos advindos com a aplicação pura, simples e literal 
dela, presumindo, no entanto, que há bons argumentos para sua aplicação. Diante de tal percurso, diferente dos modelos formalista puro, particularista e particularista sensível às regras, como visto, tem-se a possibilidade de manter a aplicação de uma regra de competência recorrendo-se aos propósitos ou princípios justificadores com a finalidade de responder às teses ativistas que buscam sua superação.

Assim, é uma espécie de estratégia para evitar a concentração de poderes nas mãos dos juízes, pois dificilmente seria justificável uma excepcionalidade capaz de superar uma regra de competência, conferindo-se mais poder a partir de uma interpretação auto-interessada do próprio Poder Judiciário.

\section{Referências}

ALEXY, Robert. Teoria dos direitos fundamentais. Tradução de Virgílio Afonso da Silva. São Paulo: Malheiros, 2008.

AGAMBEN, Giorgio. Estado de exceção. Tradução de Iraci D. Poleti. $2^{a}$ ed. São Paulo: Boitempo, 2004. Kindle edition. Posição 199 de 2202.

ÁVILA, Humberto. "Neoconstitucionalismo": entre a "ciência do Direito" e o "Direito da ciência”. Salvador: REDE - Revista eletrônica de Direito do Estado, número 17, 2009.

ÁVILA, Humberto. Teoria dos princípios - da definição à aplicação dos princípios jurídicos.

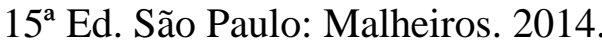

CAMPBELL, Tom D. The legal theory of ethical positivism. New York: Routledge, 2016. Kindle edition.

CHALMERS, A. F. O que é ciência afinal? Editora Brasiliense, 1993.

DIMOULIS, Dimitri. Positivismo jurídico. Introdução a uma teoria do Direito e defesa do pragmatismo jurídico-político. São Paulo: Método, 2006.

HART, H. L. A. O conceito de Direito. Tradução de Antônio de Oliveira Sette-Câmara. São Paulo: Martins Fontes, 2012.

SERRANO, Pedro Estevam Alves Pinto. Autoritarismo e golpes na América Latina. Breve ensaio sobre jurisdição e exceção. São Paulo: Alameda, 2016. Kindle edition. Posição 1676.

SCHAUER, Frederick. Formalism. The Yale Law Journal. Vol. 97, No , 4. Mar. 1988.

SCHAUER, Frederick. Exceptions. The university of Chicago law review. Vol. 58, n 2, 1991B.

SCHAUER, Frederick. Playing by the rules. A philosophical examination of rule-based decision-making in law and in life. Claredon Press, Oxford, 1991. Kindle edition. 
SCHAUER, Frederick. Rules and the rule of law. 14. Harv. J.L. Pub. Pol'y645 (1991C).

STRUCHINER, Noel. Os positivismos de Frederick Schauer. IN. O positivismo jurídico no século XXI. TORRANO, Bruno; OMNATI, José Emílio Medauar (Coord.). Rio de Janeiro: Lumen Juris, 2018.

TORRANO, Bruno. Democracia e respeito à lei. Entre positivismo jurídico e pós-positivismo. Rio de Janeiro: Lumen Juris, 2015. p, 15.

WALDRON, Jeremy. Normative (or ethical) positivism. In.: Hart's postscript. Essays on the postscript to the concept of Law. Oxford: Oxford University Press, 2005. 